\title{
《三国演义》与《东周列国志》描写战争艺术之异同
}

\author{
段海宇
}

西南民族大学文学与新闻传播学院

DOI:10.32629/er.v3i4.2618

[摘 要] 中国古代历史演义小说源远流长, 优秀的文学作品不断涌现, 而尤以《三国演义》和《东周列国志》最为特出。描写战争艺术是二者 十分重要的组成部分, 笔者通过对《三国演义》和《东周列国志》重大战役进行艺术进行对比研究, 揭示二者在战略与战术、人谋与地势以及形 象与性格等方面的异同,从而更深层次地挖掘二者战争艺术理论启迪的深刻意义。

[关键词] 《三国演义》; 《东周列国志》; 战争艺术

\section{1 战争环境描写之异同}

《三国演义》写了很多战争, 每一次战争都写得很独特、五彩缤纷, 为广大读者开启了一幅精彩细烂的战争画面。为什么 《三国演义》能以不 同的方式写每一场战争, 并有自己的特点呢?人们进行了大量的讨论和分 析, 比如战争的特点、战略战术的运用和人物活动等, 人们只从侧面去分析 《三国演义》的战争艺术, 很少去分析中战争的环境。但是, 对每一次战争 的典型环境描写都突出了战争的特征。战争的典型环境包括: 自然环境和 政治、军事环境。政治、军事环境包括战争原因、庙堂谋略、外交往复和 民心向背等。因此, 要记录每场战争的特点, 首先必须写出典型环境。写出 每次战争自然、政治、军事的典型环境, 这样战争的特点就害然醒目, 一目 了然。

\section{1 《三国演义》战争环境描写之特点}

《三国演义》往往以历史史实为基础, 把每次战争的自然、政治、军 事形势的环境色彩描写得浓艳强烈, 创造出一种特有的浓重气氛, 特别是 对战争的自然环境描述。如 “博望坡军师初用兵”, 并不是很大规模的战 斗。然而, 作者为了突出孔明用火烧曹营的战争特点, 就把典型环境进行了 十分清晰的描写。在自然环境方面: “左有山, 名曰豫山右有林, 名曰安林”, “南道路狭, 山川相逼, 树林丛杂”, “两边都是芦苇”; 又在这浓云密布、 月黑风高、刮着大风的晚上。这样的自然环境, 给诸葛亮的火攻提供了便 利。政治、军事环境方面: 曹操打败袁绍, 极大增强了他的威信, 并派夏侯 淳带领十万大军去剿灭刘备; 刘备当时只是驻守在新野这个弹丸小地, 诸 葛亮才出山, 兵不满万, 势单力薄。面对如此的政治、军事环境, 诸葛亮选 择了火攻智胜。而夏侯淳的自负轻敌, 正好为诸葛亮火攻提供了可能性。 正是作者反复强调了这些特定的典型环境, 就把这次战争火攻的特点烘托 出来, 顿时就豁然鲜明了许多。

“烧藤甲七擒孟获” 也是如此。诸葛亮在六擒六放孟获后, 孟获仍然 不服气, 于是去说服元突骨领着三万藤甲军去讨伐诸葛亮。那藤甲军 “俱 穿藤甲; 其藤生于山涧之中, 盘于石壁之上; 国人采取, 浸于油中, 半年方 取出晒之, 晒干复浸, 凡十余遍, 却才造成恺甲; 穿在身上, 渡江不沉, 经水 不湿, 刀箭皆不能入”。结果, 蜀兵和他们交战, 没有办法阻挡藤甲军, 都败 下阵来了。这样的军事形势, 对诸葛亮来非常不利的。诸暮亮只能用智取 的办法来破这三万藤甲军, 而且解决问题唯一的途径就是用火攻。但孟获 与诸葛亮交手了很多次, 深知诸葛亮善长使用计谋。因此, 每当到山谷有很 多树木的地方, 孟获就提醒元突骨不能轻易的往前走, 让他堤防诸葛亮的 埋伏。诸葛亮就利用敌人的心理, 不再在树木茂盛的地方埋伏, 而在敌人认 为不可能伏击的盘蛇谷却设下埋伏。那磐蛇谷 “形如长蛇, 皆光峭石壁, 并无树木, 中间一条大路”, 几笔就把自然环境就描写得极为清楚和突出。 当时的军事形势、敌人心态以及地理、自然环境, “火烧藤甲军” 的特点
也就跃然纸上了。

自然环境和政治、军事形势对每次具体的战争特点都有影响。《三国 演义》中的典型环境, 不仅能突出两方面的环境都描写得很突出, 又可以将 二者同时并重; 但也可以只突出一个方面。但是《三国演义》主要是侧重 于地理、自然环境的描写, 上述 “博望坡军师初用兵”、“烧藤甲七擒孟获” 就是着重偏重于地理、自然环境, 政治、军事形势则是稍微显得不那么鲜 明突出。

\section{2 《东周列国志》战争环境描写之特点}

《东周列国志》更擅长对大规模的战争描写, 几次大规模战争的描写 得很出色。对于战争环境的描写, 不单是描写地理、自然环境, 而是把重点 放在政治问题上, 把战争看作是非常复杂的政治斗争和军事斗争来做全面 的描写。作者认为政治问题是战争胜败的关键, 重视战争的本质。因此, 作者在描写大规模战役时, 总是在恰当的时候暗示出双方结局。而战争的 过程总是略写, 只强调战术的运用。在描写战争的过程中, 虽是作者写的很 简短, 但也有一些细微的地方, 往往是几个字, 但故事情节描写的却是详细 而生动。号称五大战役之一的《晋楚城兴之战》以指挥者的指挥为主线, 用对照的手法, 有序地描写了战争的全过程, 战场上的直接对抗篇幅很少 (一小段), 主要是讲述战前双方的外交斗争: “使宋舍我而赂齐、秦, 藉之 告楚。我执曹君而分曹、卫之田, 以赐宋人。楚爱曹、卫, 必不许也。喜赂 怒顽, 能无战乎?” (着重写晋国利用矛盾), 民心向背 (楚成王指出晋侯 “有 德不可敌”, 以及晋军立足道义 “退避三舍”) 、君臣关系与军队的士气 (楚 王的 “少与之师”、“楚众欲止, 子玉不可”、晋 “战车七百乘”, “少长有 礼、士气高昂”), 进而暗示了战争的结局和原因。

《东周列国志》对战争的环境, 都着重对战前准备的描写, 对于战争 经过都是比较简略。特别注意从战争双方在战略和战术两方面揭示战争 双方政治、道德的优势、利弊, 以及如何利用自己的优势把被动改为主 动的过程, 上述力量转化的结果决定了战争的胜负。“作者擅长把每一个 战争都放在大国争霸的环境下进行描写, 对于战争的起因、经过、各国 之间的关系组和变化、战前的策划及战争的影响等等, 都有着大量的篇 幅”。《城榉之战》是一次重大战役, 作者先写晋、楚、宋、卫、曹之间 的对抗与结盟; 在短短的数百字里就写出了晋国佯装败退, 引敌深入, 然 后打败楚军的过程。同时, 他也生动地描绘了战场的壮观场面。作者十 分注重对双方将领的道德修养、军事素质以及精神风貌的描写。三军将 领的人选也是非常重要的, 它决定着战争的胜败。晋国在组建军队时, 就 说明军中将领的任用条件是 “敦诗书而说礼乐”, 同时强调军队主帅的 文化素养、道德素质等。

\section{2 战争谋略展现之异同}

在《三国演义》和《东周列国志》中, 从统治者到将帅士兵, 为了生存, 
用尽了各种各样的谋略。《三国演义》把古代兵书中所有的军事理论和军 事谋略融为一体, 把逻辑的推理和心理的分析汇聚到了一起, 把军事谋略 放到了书中故事里面去, 把《三国演义》变成了一部大众喜闻乐见的通俗 军事读物, 成为典型。

2.1 《三国演义》战争谋略展现之特点

两军交战, 勇气是不可或缺的, 但胜利仍属于智者! 正如孙子说得 “上 兵伐谋”, 双方之间的战争一旦展开, 实质上仍是对战双方的智慧和战争谋 略较量! 因此, 战争谋略展现的异同就可以从战略、战术两方面来展现。

战略上采用以人为本的谋略思想, 以赢得人心。在《东周列国志》所 描述的春秋时期, 战争本身就相当于一种政治活动。统治者为了统一各国 成为霸主, 非常重视采取一些明智的政治措施, 以获得人民的支持。大凡要 发兵开战, 各诸侯国都会找一个赢得国内支持的正当理由, 尤其是在春秋 时期打着 “尊王攘夷” 的幌子, 在战争中赢得民心, 来实现霸业。

《三国演义》更加着重于战术上的运用。如官渡之战, 袁绍依仗粮 草众多, 拒不听劝, 引七十万大军去讨伐曹操。曹操清楚自己粮草不足, 所以就采纳谋士许做的计谋, 自己亲自率领士兵扮成袁军, 冲到袁军车 粮的地方一一乌巢, 一场大火烧毁了袁绍的粮草, 使得袁军军心涣散。曹 军却士气大涨, 一举赢得了官渡之战的胜利。所以, 在一定程度上粮草决 定了官渡之战的胜败。诸葛亮六出祁山, 前四次是因为长途作战, 粮草未 随而放弃。诸葛亮第五次出征祁山时, 一方面解决远距离作战时造成的 将士疲劳问题, 另外一方面用疑兵之计, 使得司马懿不敢冒然出兵。诸葛 亮却在暗中让士兵将陇上成熟的小麦迅速收割完成, 军队粮草的短缺问 题也顺势解决了。诸葛亮第六次出祁山时, 建造木马牛车来供剑阁、祁 山两个地方的粮草运输使用。司马懿命令士兵抢到了数辆木马牛车, 拿 回来加以仿制, 也想用来运输粮草, 不料想中了诸葛亮的计, 运输粮草的 木马牛车全部被劫。司马懿带军来营救, 却也只能被伏军打败, 落得个丢 盔弃甲而逃。

2.2 《东周列国志》战争谋略展现之特点

《东周列国志》中也不乏战术的运用, 例如 “骊姬巧用妙计杀申生 和越王勾践将西施送给夫差, 都是美人计运用的典范”。但是《东周列国 志》主要是侧重于战略上的运用了。譬如《孙子兵法》中提出了 “兵贵 胜, 不贵久。兵闻拙速, 未睹巧之久也。夫兵久而国利者, 未之有也。” 在 春秋时, 战争的规模已经是大了: “驰车千驰, 革车千乘, 带甲十万”, “日 费千金”。当时社会生产力很低, 长期作战的话, 势必消耗巨大的人力、 财力, 影响人民的正常生活。所以, 战争基本在短期内就结束了。然而到 了战国时期, 社会生产力水平提高了, 各国实力的大大增强了, 战争的时 间增加到了数月乃至数年。但是, 交战时间越长, 国力损耗就越大, 这就 对各诸侯的争霸不利, 所以 “速胜” 还是一种最为稳妥的办法。想要达 到 “速胜”, 除了征战之外, 国内也必须做好战前的准备, 例如发展生产, 经济改革, 扩大贸易, 增加财政收入等。所以 “养兵千日, 用兵一时” 成 为当时的战争特点

在《东周列国志》中为了巩固楚国的地位和自己的统治, 楚平王开始 对国家进行政治, 同时颁布了许多措施: “分贫, 振穷, 长孤幼, 养老疾; 收 介特, 救灾患, 育孤葟, 赦罪决; 洁奸德, 举淹滞……息民五年, 而后用师”, 从此可知, 休养生息对国家军事实力的增强有着突出的作用。晋悼公从征 讨郑国回来之后, 就采取很多的政策让人民休养生息, 逐渐使国家强盛。所 以三次起兵, 楚国都不能打败晋国。越王勾践也吸取了教训, 开始大力发展 生产力, 有了的物质基础后, 就打败强大的吴国。这些都是《东周列国志》 在战略上比较有代表性的一部分。

3 战争人物刻画之异同
战争艺术最为根本的就是人物刻画, 如《左传》、《史记》。《三国演义》 主要以战争来刻画人物, 同时结合战争的发展过程。如赤壁之战中, 通过 “舌战群儒”, 体现了诸葛亮的才能。周瑜嫲妒诸暮亮, 几次想为难诸葛亮, 都被诸葛亮化解。作者在描写周瑜和诸葛亮的交手中, 用对比的手法来展 现不同的人物性格特征, 一个才华横溢但气量不足, 导致聪明反被聪明误; 一个则基于全局, 稳操胜券。在赤壁之战中, 作者还写了蒋干的愚而自用, 鲁肃的忠厚老实, 黄盖的忠心耿耿等。把不同的人物形象生动的描绘出来, 让读者无法忘记。在赤壁之战中, 就通过战争的发展以及人物在战争地位 的不一样, 对关羽、张飞的人物性格进行深入的刻画。

3.1 《三国演义》战争人物刻画之特点

《三国演义》一直把人物刻画置于重要位置。通过战争的进程结合人 物的活动, 使用对比、烘托、渲染等技巧手法来刻画人物, 揭示人物的形象。 这也契合了战争艺术兵贵神速、紧张激烈、不加以精雕细刻的实际情况。 例如 “温酒斩华雄” , 便是用侧面祄托与虚写相结合的手法去刻画关羽形 象。整段文字通过人物之间的关系, 采用烘托、映祄等技巧来突出关羽是 如何英勇战斗、如何惊险紧张。首先是把华雄描写的很高大、英勇, 从侧 面祄托出关羽的形象更高大、英勇。其次就是关羽不非同寻常的出场方式, 孙坚损兵折将的 “伤感” , 袁绍听后的 “大惊”, 诸侯的 “并皆不语” 等。 而此时刘关张三人只是 “冷笑”: 笑对华雄一筹莫展的诸侯, 也笑放肆临时 的华雄。此时情形中关羽的出场特别引人注目, 很沉稳、很自信。然后还 是没有直接进入战斗, 而是从酒的渲染上, 曹操为关羽倒酒, 是为了祝他成 功凯旋, 也是为了激励他, 为他壮行。但在这个时候, 关羽并没有喝酒, 只说 了一句 “某去去便来”, 普通而又不寻常的四个字, 把一个高俊自傲的英雄 形象写的非常生动。战争的具体场景只有六十三个字, 很精炼、简洁。“变 铃响处”, 关羽已经拿下华雄的人头, 而这时 “其酒尚温”。尽管它是直接 写战争的, 但一个字也没有, 读者却可以从帐外的鼓声、呐喊声, 以及诸侯 失色的表情, 可以知道战斗的激烈紧张, 关羽的高大威猛、沉着冷静以及骁 勇善战的人物形象。

3.2 《东周列国志》战争人物刻画之特点

而《东周列国志》有其自身的特点, 战争艺术的人物刻画具有开放式 的特征。从而使战争艺术形成了 “每事自为一章” 这一格局。在这方面, 就和《三国演义》有明显的不同。“《三国演义》都是重点描写主要人物, 通过主要人物与各人物、事件的关系来描写主要人物, 同时围绕着主要人 物来选取材料、设置情节”。而在描写《东周列国志》战争艺术时, 通常是 考虑到了到战争的整个过程和参战各方的活动, 把战争各个阶段的人物一 个接一个的展开来, 以刻画多个人物形象来展现战争的发展过程, 在人物 刻画上表现出开放式的特征。在这几个重大战役的描述中特别明显，《必 之战》中描写的人物多达五十多个, 有三十多人出场不止一次, 而绝大多数 人物出场三到五次, 其中有些出场高达十次之多。《鄢陵之战》描述的是对 三十多人的战争活动, 其中一些甚至出现了七次。作者并不是一味地去表 达人物, 而是根据人物在战争中的地位去选择刻画的对象。

此外, 战争艺术在人物性格刻画上有着片段式特征。战争艺术以时间 为前提, 在《东周列国志》中, 可以从整体上的战争艺术中看出。《东周列 国志》中一些人物经历的事件更多, 时间跨度更大。作者用多种方式对他 们进行长时间和多场合的描述, 形成一个比较完整的人物发展史, 比如郑 子产、楚灵王等。与人物性格发展史比较, 战争艺术所说的是人物性格间 的实际关系。

因为战争艺术的内容不一样, 所以战争的规模也是不一样的。所以在 刻画人物时, 不仅存在着人物的横向表现, 而且还有着垂直发展。在《东周 列国志》中, 通过不同活动的不同事件和场合中来刻画人物多方面思想特 


\section{二语课堂互动中同伴支架探析}

邓莘

江西师范大学

DOI:10.32629/er.v3i4.2593

[摘 要] 二语课堂互动在应用语言学领域一直受到广泛关注, 最近研究表明在二语课堂互动中除了教师支架之外, 同伴支架也能促进学习者的 二语学习。本文旨在围绕二语课堂互动中同伴支架的含义、实证研究、不足以及对我国二语课堂教学的启示进行探析。

[关键词] 同伴支架; 二语课堂互动; 二语学习

\section{引言}

互动作为课堂信息输入和输出的重要手段, 在促进二语课堂教学中发 挥着重要的作用。课堂互动包括师生互动和生生互动两种。从互动人数方 面来看, 生生互动包括结对互动与小组互动。结对互动和小组互动相关研 究的出现是社会文化理论里的支架这一概念被应用到了同伴互动活动中 的具体体现。早期的二语课堂研究往往聚焦于教师支架, 强调教师作为专 家为语言学习者提供协助; 而最近二语课堂研究越来越关注同伴支架, 强 调学生在生生互动中为同伴提供帮助。

\section{1 同伴支架的定义}

“支架” (scaffolding) 起源于前苏联心理学家维果斯基的社会文 化理论中的“最近发展区” (ZPD), 但维果斯基却从来没有使用过 “支架” 这一词, 而是强调 “中介” 的作用, 后来支持维果斯基观点的布鲁纳等学 者在 “支架” 和 “最近发展区”之间建起了真正的联系, 并基于 “最近 发展区” 提出了支架这一概念, 即在儿童所达到的解决问题的潜在水平 里他人对儿童所提供的协助被称为支架。支架被运用到了二语课堂教学 中, 成为了一种比较受欢迎的教学方法一支架式教学, 但以强调教师支 架为主。学者Donato (1994) 通过一项口语研究发现第一次正式地提出了 同伴支架 (peer scaffolding) 这一概念。同伴支架指的是在课堂互动中 拥有新手和专家两重身份的学习者为同伴搭建支架以共同解决同伴互 动中所遇到的无法通过一己之力解决的问题, 而且其在促进学习者二语 学习方面得到了不同理论的支持, 其中包括合作学习理论, 社会文化理 论和情感过滤假说。

\section{2 实证研究}

同伴支架的研究于 20 世纪90年代开始出现, 国外学者Donato (1994) 通 过微观分析法研究三名母语为英语的法语学习者的口语互动发现同伴学 习者在口语互动过程中, 彼此互相搭建支架, 不断地尝试以达到形式和意
义的正确表达。在另一个类似的研究中, Ohta (2000) 通过分析两名受试者 使用交际性的任务来学习日本语法的口语对话发现,一位受试者在另一位 受试者的帮助下, 通过彼此互动, 渐渐地能将日语语法规则内化并且将其 灵活运用, 从而完成语法任务, 学会了日语语法。这也说明了不同水平的学 习者互相搭建支架能促进流畅的语言输出。Storch (2007) 在开展的写作任 务中观察受试者的同伴互动话语也得出了类似的结论, 同伴互相搭建支架 能够为学习者提供更多使用目标语交流和输出的机会, 目标语输出的机会 越多, 目标语输出地越流畅。

近年来, 国内的实证研究开始重视并且证实了同伴支架对英语课堂互 动中学习者二语学习的积极作用。李玲 (2015) 在研究了四名高考英语笔试 成绩相当口语成绩不一大一新生的口语练习及以小组互动的形式开展的 口语对话后发现这四名学习者在彼此互相搭建的同伴支架的互动过程中 能纠正彼此目标语中出现的错误, 增加学习者表达目标语的机会, 从而提 高学习者正确表达目标语形式的能力。徐锦芬 (2016) 开展了一项关于非英 语专业大一的学生在英语课堂小组互动中给同伴搭建支架实验研究后发 现同伴支架作用主要表现在提高参与度、提供词汇、提供观点、纠正错误 表达、简化任务、维持既定目标、控制挫败感七个具体方面。张秀芹和贺 玉珍 (2018) 进行了一项为期十周的大学英语专业大一学生网络文本互动 和英语课堂互动的对比实验后发现在两种试验中同伴支架均发挥了一定 的作用且在纠正错误表达和提供词汇方面课堂互动中的同伴支架数量比 网络文本互动高。

\section{3 同伴支架的局限性}

首先, 学习者二语水平不够会影响学习者在生生互动中有效地给同伴 搭建支架, 具体体现如下: (1) 学习者在生生互动过程中对同伴的表现所给 出的反馈大多是二语的形式或语义的表面反馈, 缺少实质意义上的纠正性 反馈, 因此有时很难达到反馈的预期效果; (2) 学习者在二语课堂中有时不
征, 反映人物在短时间内的垂直发展。如《崤之战》中的秦穆公, 作者从他 进攻郑国写起, 通过拒谏、叱骂赛叔以及向师悔过, 反映了他在大战前后的 性格变化。秦穆公身上有着刚惶自用、忌恨贤臣和勇于改过自新等特点, 表现出了性格的复杂性。然而从《东周列国志》中看, 《崤之战》中对秦 穆公描写只是人物性格发展史的一个环节。《东周列国志》还写了秦穆公 举贤任能、讲究礼义和称霸西戎等事情, 在很长时间和众多事件中, 写出了 秦穆公的性格发展史, 类似还有晋文公、郑庄公等。他们的性格, 既有在《东 周列国志》中的垂直发展, 也有在战争中的横向展示。有些人物经常出现 在几个相邻的战斗中。通过不同的描写, 可以看到他们性格多方面的变化。 其他如楚子玉、晋吕特、荷林父等人, 也出现在不同的章节里, 从他们在不 同战争中, 就可以看出他们性格的多样性。
[1]草夫.《三国演义》的战争环境描写[J].椰州师专学报,1995(3):19-20. [2]徐剑凌.《三国演义》的战争描写手法[J]. 攀枝花大学学报,2000(1):35-37. [3]孙谦.《三国演义》战争描写艺术散论[J].龙岩师专学报,1995(02):8-12. [4]刘斯龙. 《三国演义》战争描写的美学特征[J].阅读与写作,1999(1):21. [5]王亚华.《三国演义》的战争艺术分析[J].安徽文学月刊,2011(7):135-136. 作者简介:

段海宇 (1995--), 男, 白族, 云南丽江人, 西南民族大学文学与新闻 传播学院中国国代文学硕士研究生,研究方向: 少族民族文学。

\section{项目基金:}

西南民族大学研究生创新性科研项目《三国演义》与《东周列国 志》描写战争艺术之异同；项目编号：CX2020SP43。

\section{[参考文献]}

